\title{
EL EJÉRCITO ARGENTINO Y LA GUERRA CONVENCIONAL EN LA SEGUNDA MITAD DEL SIGLO XX. REFLEXIONES A PARTIR DE LA EXPERIENCIA DE LA ARTILLERÍA EN LA GUERRA DE MALVINAS
}

\author{
GERMÁN SOPRANO \\ IdIHCS-CONICET-UNLP \\ gsoprano69@gmail.com
}

\section{Resumen:}

Este artículo tiene por objetivo analizar dos cuestiones relacionadas con la participación del Ejército Argentino en la Guerra de Malvinas. Por un lado, la diversidad de perspectivas y experiencias vividas por los combatientes argentinos en esa guerra, particularmente, centrándonos en el Grupo de Artillería 3. Por otro lado, una cuestión menos estudiada en la historia reciente de la Argentina: la preparación militar para la guerra convencional. En consecuencia, sin descuidar la importancia de la denominada "Doctrina de la Seguridad Nacional" en las concepciones del conflicto e intervenciones represivas de las Fuerzas Armadas entre 1956-1983, afirmamos que es necesario profundizar complementariamente nuestros conocimientos sobre la educación de los militares y la instrucción, adiestramiento y alistamiento de sus unidades para la guerra convencional, especialmente, en función de hipótesis de conflicto con Chile y Brasil.

Palabras clave:

Guerra convencional, Guerra de Malvinas, Ejército Argentino, artillería, segunda mitad siglo XX

\begin{abstract}
:
This article aims to analyse two issues related to the participation of the Argentine Army in the Falklands War. On the one hand, the diversity of perspectives and experiences of the argentine fighters in that war, in particular, focusing on the 3rd Artillery Group. On the other hand, a lessstudied issue in the recent history of the Argentina: military preparing for conventional warfare. As a result, without neglecting the importance of so-called "national security doctrine" in the conceptions of conflict and repressive interventions from the Armed Forces between 1956-1983, we affirm that it is necessary -to additionally- deepen our knowledge about the education of military and instruction, training and enlistment of its units for conventional warfare, especially based on hypothesis of conflict with Chile and Brazil.
\end{abstract}

\section{Keywords:}

Conventional warfare, Falklands War, Argentine Army, artillery, the second half of the 20th century 


\title{
EL EJÉRCITO ARGENTINO Y LA GUERRA CONVENCIONAL EN LA SEGUNDA MITAD DEL SIGLO XX. REFLEXIONES A PARTIR DE LA EXPERIENCIA DE LA ARTILLERÍA EN LA GUERRA DE MALVINAS
}

\author{
GERMÁN SOPRANO \\ IdIHCS-CONICET-UNLP \\ gsoprano69@gmail.com
}

\section{Introducción}

Este artículo tiene por objetivo analizar dos cuestiones relacionadas con la participación del Ejército en la Guerra de Malvinas, la única guerra convencional que las Fuerzas Armadas Argentinas libraron en el siglo XX. Por un lado, nos ocuparemos de una cuestión problematizada por antropólogos e historiadores argentinos que comprendieron una pluralidad de perspectivas y experiencias de guerra vividas por los combatientes -oficiales, suboficiales y soldados conscriptosde diferentes unidades militares y de acuerdo con sus emplazamientos en el Teatro de Operaciones Malvinas o el Teatro de Operaciones del Atlántico Sur. Particularmente nos centraremos en el caso del Grupo de Artillería 3, una unidad conducida por el entonces teniente coronel Martín Antonio Balza que participó en forma decisiva de la defensa perimétrica de Puerto Argentino. Por otro lado, a partir del conocimiento de este estudio de caso reflexionaremos acerca de una cuestión menos transitada en las investigaciones sobre historia reciente de la Argentina: la preparación militar para la guerra convencional. En este sentido, el buen desempeño de algunas unidades tácticas del Ejército -artillería de campaña, artillería antiaérea, compañías de comandos y algunos elementos de infantería- en la Guerra de Malvinas permite reconsiderar los alcances sustantivos de la interpretación dominante acerca de una Fuerza sólo preparada para atender hipótesis de conflicto internas entre 1956 y 1983. En consecuencia, sin descuidar la importancia de la denominada "Doctrina de la Seguridad Nacional" en la definición de las concepciones del conflicto e intervenciones represivas de las Fuerzas Armadas en esos años, afirmamos que es preciso -en forma complementaria- profundizar nuestros conocimientos sobre la formación y el perfeccionamiento de los militares y de la instrucción, adiestramiento y alistamiento de sus unidades operativas (considerando las armas de infantería, caballería, artillería, ingenieros y comunicaciones) para la guerra convencional, especialmente, en función de hipótesis de conflicto con Chile y Brasil.

Para dar cuenta de ambas cuestiones nos serviremos, por un lado, de entrevistas que efectuamos a oficiales, suboficiales y soldados conscriptos veteranos del Grupo de Artillería 3 en el marco de la investigación para la elaboración de una biografía del teniente general VGM (R) Martín Antonio Balza y, por otro, de fuentes como el Libro Histórico y el Diario de Guerra de esa unidad, reglamentos militares y artículos publicados en la Revista de la Escuela Superior de Guerra y otros documentos oficiales del Ejército.

\section{Las Guerras de Malvinas}

Algunas investigaciones de científicos sociales han reconocido y comprendido en sus singularidades las perspectivas y experiencias en y sobre la Guerra de Malvinas de oficiales, suboficiales y soldados conforme a la jerarquía, trayectoria y roles que estos cumplían en la 
cadena de mando castrense, las características orgánico-funcionales de las organizaciones militares en las que aquellos actores sociales se inscribían y los emplazamientos que ocuparon sus unidades en el conflicto bélico. ${ }^{1}$

El precursor estudio antropológico de Rosana Guber De chicos a veteranos. Memorias argentinas de la guerra de Malvinas -cuyo trabajo de campo etnográfico efectuó en 1989 y entre 1991 y 1993- se centró principalmente en las memorias de soldados conscriptos oriundos o radicados en diferentes provincias argentinas y combatieron en distintas unidades militares, pero también incorporó las de oficiales y suboficiales del Ejército, Armada y Fuerza Aérea Argentina. ${ }^{2}$ Destaca que una de las consecuencias que tuvo esta guerra fue la conformación de una nueva identidad social definida por su pertenencia nacional, de edad y por su participación directa en el Teatro de Operaciones del Atlántico Sur entre el 2 de abril y el 14 de junio de 1982: los "ex-soldados", "chicos", "ex-combatientes" o "veteranos de Malvinas". ${ }^{3}$ Posteriormente continuó sus investigaciones sobre Malvinas enfocándose en las memorias navales de la Armada y en las destacadas experiencias de los pilotos de los aviones de combate A4B de la Fuerza Aérea. ${ }^{4}$

En la historiografía son referencia ineludible los estudios iniciados por Federico Lorenz en 1995, dando cuenta también de esa diversidad de perspectivas y experiencias de los combatientes. Cuando publicó Las guerras por Malvinas propuso comprender las "distintas formas" en que la guerra "fue vivida" y "explorar las relaciones entre la experiencia de los actores, protagonistas y testigos voluntarios o involuntarios de una guerra y sus consecuencias". ${ }^{5}$ En ese libro se

\footnotetext{
${ }^{1}$ Esta sección del artículo no pretende ser un estado del arte sobre la producción académica en ciencias sociales sobre la Guerra de Malvinas sino, como he explicitado arriba, una forma de posicionar mis argumentos en relación con aspectos de la prolífica producción de colegas que se han especializado en el estudio de esa guerra y las perspectivas, experiencias y memorias de sus combatientes y no combatientes argentinos. Por tal motivo, las referencias bibliográficas en modo alguno no son exhaustivas. Asimismo, al establecer una interlocución prioritaria con las investigaciones de científicos sociales que estudiaron el tema desde ese enfoque, no pretendo desconsiderar el aporte analítico ofrecido por las perspectivas cultivadas por otros estudiosos civiles y militares ni por la literatura testimonial producida por veteranos de la Guerra de Malvinas.

2 Guber, Rosana, De chicos a veteranos. Memorias argentinas de la guerra de Malvinas, Buenos Aires, Antropofagia, 2004.

${ }^{3}$ Las diversas experiencias reconocibles en esos soldados conscriptos no solo se asocia con su participación en distintas unidades militares en el conflicto bélico, sino por sus heterogéneos orígenes y trayectorias sociales previas y posteriores a la Guerra de Malvinas. Al respecto, Guber sostiene: "Procedían prácticamente de todas las provincias argentinas, de parajes inhóspitos y de áreas metropolitanas, de familias profesionales y obreras, de comerciantes y de peones rurales, de ascendencia indígena, europea, asiática, criolla y latinoamericana. Muchos de estos jóvenes eran ya trabajadores, otros eran estudiantes y otros pretendían continuar con la carrera militar, los había empleados y oficinistas, obreros y pastores, labradores y desocupados; algunos ya eran activistas o simpatizantes de partidos políticos todavía prescriptos o bajo la veda impuesta por el régimen desde el 24 de marzo de 1976; y, aunque es difícil saberlo con precisión, es muy probable que una amplia mayoría no ostentara por entonces militancia política alguna". Guber, Rosana, De chicos a veteranos... op.cit.p.15.

${ }_{4}$ Guber, Rosana, "Crucero ARA General Belgrano in memóriam. Linajes político-navales en las memorias de Malvinas", Revista de Ciencias Sociales Iberoamericana vol.30, 2008, Berlín, pp.7-26. Guber, Rosana, Experiencia de halcón, Buenos Aires, Sudamericana, 2016.

${ }^{5}$ Lorenz, Federico. Las guerras por Malvinas, Buenos Aires, Edhasa, 2006, p.15. Al abordar las distintas formas en que la guerra fue vivida, Lorenz se ocupó de perspectivas y experiencias de combatientes y no combatientes. Así por ejemplo se enfocó en estos últimos en: Lorenz, Federico, "Otras marcas. Guerra y memoria en una localidad del sur argentino (1978-1982)”, en: E. Bohoslavsky, M. Franco, M. Iglesias y D. Lvovich (comps.), Problemas de historia reciente en el Cono Sur, vol. 1, Buenos Aires, Universidad Nacional de General Sarmiento / Prometeo, pp.125-146. Al tiempo que en otro trabajo Lorenz señaló el impacto diferencial que la experiencia bélica y la derrota en la guerra impactaron en las identidades profesionales de las tres Fuerzas Armadas y en las apreciaciones públicas sobre aquellas producidas por sus conciudadanos: en el Ejército se produjo una división horizontal entre "malvineros" y "no malvineros", entre "oficiales de escritorio" y "oficiales con mando de tropa", que haría su eclosión en la crisis de los "levantamientos carapintada" de abril de 1987, enero y diciembre de 1988 y diciembre de 1990. En la Armada se "cimentó la idea social de una fuerza que no había combatido", pero tuvo grandes pérdidas humanas con el hundimiento del buque ARA General Belgrano. Y en la Fuerza Aérea los pilotos tuvieron una "excelente imagen social ya durante la guerra" y -posiblemente por ello- no experimentó “confrontaciones internas" tras la derrota. Lorenz, Federico, Malvinas. Una guerra argentina, Buenos Aires, Sudamericana, 2009, pp.175 y ss.
} 
concentró en los conscriptos o "ex-soldados combatientes". Asimismo en un artículo más reciente Lorenz destacó la singularidad de las perspectivas y experiencias de guerra reconocibles a partir del análisis de los emplazamientos que tuvieron las unidades militares, en particular, abordando el caso de aquellos oficiales del Ejército destinados con sus unidades en la Isla Gran Malvina -el Regimiento de Infantería 5, compañías del Regimiento de Infantería Mecanizado 8 y la Compañía de Ingenieros 9- que quedaron aisladas tras el desembarco británico en el Estrecho de San Carlos el 21 de mayo de 1982 y padecieron hambre por causa del desabastecimiento y el hostigamiento de las fuerzas enemigas prácticamente sin poder entrar en combate. ${ }^{6}$

Por su parte, las investigaciones del politólogo Alejandro Corbacho y los historiadores Andrea Belén Rodríguez y Pablo Melara estudiaron las particulares vivencias de la Guerra de Malvinas del personal la Armada Argentina destinado en el Teatro de Operaciones Malvinas: el Batallón de Infantería de Marina 5, el Apostadero Naval Malvinas y la Agrupación de Buzos Tácticos, respectivamente. ${ }^{7}$ Por último, la antropóloga María Pozzio se ocupó de la original experiencia de las mujeres enfermeras enviadas a las islas como personal de sanidad militar. ${ }^{8}$

En definitiva, las guerras son fenómenos colectivos y, como tales, reconocemos entre ellas similitudes y diferencias históricamente dadas. A su vez, las vivencias de los combatientes de una guerra también revelan similitudes y diferencias colectivas e interindividuales. Una lectura de los trabajos de los científicos sociales mencionados nos permite llamar la atención acerca de las diversas perspectivas, experiencias y memorias producidas en torno de la Guerra de Malvinas conforme a las posiciones y roles sociales ocupados por sus protagonistas en sus organizaciones militares y en relación con el emplazamiento y participación de sus unidades en los combates. Teniendo en cuenta esta hipótesis, buscaré a continuación destacar algunas especificidades de una unidad del Ejército: el Grupo de Artillería 3.

\section{El Grupo de Artillería 3}

Su jefe era el teniente coronel Martín Antonio Balza. Desde que ingresó como cadete al Colegio Militar de la Nación a principios de 1952 hasta que asumió como jefe del Grupo de Artillería 3 de Paso de los Libres (provincia de Corrientes) en diciembre de 1979, transcurrieron casi veintiocho años en los que se preparó para conducir una unidad militar en una guerra convencional realizando cursos de perfeccionamiento, actividades en distintos destinos operativos y participando en una misión internacional. En ese extenso período fue:

- Cadete del arma de artillería en el Colegio Militar de la Nación (1952-1955).

\footnotetext{
6 Lorenz, Federico, "Gran Malvina. Una mirada a la experiencia bélica desde los testimonios de sus oficiales". Anuario Colombiano de Historia Socialy de la Cultura vol.41 No2, julio-diciembre de 2014, pp.225-257.

7 Corbacho, Alejandro, "Factores organizacionales y desempeño en combate: la experiencia de la IMARA en Malvinas", Serie Documentos de Trabajo No255, Buenos Aires, Ucema, 2003, pp.1-24. Rodríguez, Andrea Belén, "Cotidianeidad y guerra. Experiencias de los integrantes del Apostadero Naval Malvinas en el conflicto del Atlántico Sur", Antítese vol.2 No4, 2009, Londrina, pp.937-968. Rodríguez, Andrea Belén, "La memoria social de los ex soldados combatientes en el Apostadero Naval Malvinas en el Conflicto del Atlántico Sur. Un análisis a través de las anécdotas recurrentes del grupo", Revista Universitaria de Historia Militar vol.4 No 8, 2015, Cádiz, pp.164-182. Melara, Pablo, 80 días en Malvinas. El accionar de la Agrupación de Buzos Tácticos durante el conflicto bélico del Atlántico Sur, Mar del Plata, Tesina de Licenciatura en Historia de la Facultad de Humanidades de la Universidad Nacional de Mar del Plata, 2010. De la extensa producción sobre la experiencia y memorias de guerra del personal del Apostadero Naval Malvinas concretada por la historiadora Andrea Rodríguez, permanece inédita su tesis de doctorado. Rodríguez, Andrea Belén, Entre la guerra y la paz: la posguerra de los ex-combatientes del Apostadero Naval Malvinas. Experiencias, identidades y memorias, La Plata, Tesis de Doctorado en Historia de la Facultad de Humanidades y Ciencias de la Educación de la Universidad Nacional de La Plata, 2014.

8 Pozzio, María, "La experiencia de las mujeres en Malvinas: de la Sanidad Militar al reconocimiento", Cuadernos de Marte. Revista Latinoamericana de Sociología de la Guerra Año 6 No8, 2008, Buenos Aires, pp.129-157.
} 
- Oficial subalterno en unidades operativas: Grupo de Artillería de Montaña de Uspallata (1956 a 1958), Grupo de Artillería Liviana de Campaña Motorizado "Brigadier General Iriarte" de Ciudadela (1959-1960) y Grupo de Artillería 3 de Paso de los Libres (19661967).

- Oficial instructor (1962 a 1964) y jefe de la División Central (1965) del Colegio Militar de la Nación.

- Cursante (1958-1959), oficial instructor (1961-1968-1969) y jefe de la División de Enseñanza y Doctrina en la Escuela de Artillería (1978).

- Observador militar en Medio Oriente (1970).

- Cursante de la Escuela Superior de Guerra del Ejército (1971-1973).

- Oficial de Estado Mayor del Comando de la IX Brigada en Comodoro Rivadavia (19741975).

- Cursante de la Escuela Superior de Guerra del Perú (1976-1977).

- Jefe del Grupo de Artillería 102 de Junín en el marco de la "Operativo Soberanía" (octubre de 1978-marzo de 1979) en ocasión de la escalada del conflicto con Chile.

- Oficial de Estado Mayor del Comando de Artillería (1979). ${ }^{9}$

Si presento este recuento de hitos en la carrera militar de Balza es para llamar la atención del lector sobre el siguiente presupuesto: disponer de un buen líder militar táctico demanda una inversión de recursos que un Estado y una sociedad sólo alcanza sosteniendo durante años y de modo continuo esfuerzos destinados a su formación básica, perfeccionamiento y actividad profesional operativa. Y aunque el obligado cumplimiento de este presupuesto no garantiza necesariamente el buen suceso de la conducción del líder táctico en la guerra, no es posible desconsiderar su importancia en los resultados de su desempeño.

Como el resto de la ciudadanía argentina, Balza tomó conocimiento de la "recuperación" de las Islas Malvinas en la mañana del 2 de abril. ${ }^{10} \mathrm{El} 6$ de abril la conducción del Ejército dispuso que su unidad fuera enviada a San Antonio Oeste en el litoral de la provincia de Río Negro. La decisión no lo tomó por sorpresa, pues contaba con su unidad alistada para el combate. En la noche del 9 de abril partieron en tren desde Paso de los Libres - con armas, municiones, vehículos y provisiones- rumbo al sur. Después de casi un día de viaje hicieron escala en la estación de Martín Coronado en el conurbano bonaerense. Por la noche trasbordaron a otro tren que los condujo a Ingeniero White donde arribaron el 12 de abril a las seis de la mañana; en una parada en el camino en la estación Coronel Pringles le informaron su nuevo destino: Puerto Argentino. Ese mismo día trasladó a una parte de sus hombres hasta la cercana Base Aeronaval Comandante Espora para embarcarlos en tres aviones de transporte Hércules C-130 de la Fuerza Aérea y dos Boeing 737 de la empresa estatal civil Aerolíneas Argentinas. Seleccionó aquellos que consideraba menos aptos para el combate y los dejó en el continente. Lo acompañaron 3 mayores, 26 oficiales subalternos, 64 suboficiales y 112 soldados conscriptos. En la madrugada del 13 de abril arribaron a Puerto Argentino. Los soldados del Grupo de Artillería 3 que llevó a las Islas Malvinas procedían de las provincias del noreste argentino, pertenecían casi en su totalidad a la clase 1962, y efectuaron su instrucción en esa unidad en el año 1981. Dicha preparación no era una capacidad que dispusieran otras unidades del Ejército que acababan de incorporar soldados de la clase 1963.

\footnotetext{
${ }_{9}^{9}$ Estos hitos en la trayectoria profesional militar han sido determinados a partir de entrevistas al teniente general VGM (R) Martín Antonio Balza y mediante el análisis de la siguiente fuente documental oficial: Ejército Argentino. Legajo Personal del Teniente General Martín Antonio Balza (duplicado).

${ }^{10}$ El siguiente relato sobre la historia del Grupo de Artillería 3 es una esquemática síntesis construida a los efectos del presente artículo en base a las entrevistas realizadas a oficiales, suboficiales y soldados veteranos de guerra de esa unidad entre diciembre de 2015 y mayo de 2016.
} 
El Grupo de Artillería 3 arribó a Puerto Argentino con 18 obuses Oto Melara calibre 105 mm con alcance de 10.200 metros que integraban las Baterías de Tiro "A", "B" y "C", un carro aguatero, una cocina rodante, dos jeeps y un camión Unimog. Estos últimos medios -así como la munición para los obuses- fueron transportados por orden de Balza junto con su unidad, contraviniendo órdenes superiores que decían que aquellos serían enviados posteriormente a las islas. Ya en Puerto Argentino ordenó la inmediata construcción de posiciones de las baterías reales y simuladas- como tarea prioritaria.

Balza tuvo una destacada participación en la guerra de Malvinas como jefe del Grupo de Artillería 3 y como coordinador del Apoyo de Fuego de la Agrupación Ejército que aseguraba la defensa perimétrica en Puerto Argentino. ${ }^{11}$ Esta última comprendía la participación de su unidad, una batería del Batallón de Infantería de Marina 5 y, posteriormente, incorporó al Grupo de Artillería Aerotransportado 4 y dos piezas de artillería SOFMA del Grupo de Artillería 101 calibre $155 \mathrm{~mm}$ -con alcance de 20.000 metros- agregadas a mediados del mes de mayo conformando la Batería de Tiro "D” del Grupo de Artillería 3. ${ }^{12}$

El Grupo de Artillería 3 estaba bien instruido y adiestrado para combatir en una guerra convencional y, por ello, su papel en la defensa perimétrica de Puerto Argentino fue destacado por protagonistas y analistas británicos que ponderaron su desempeño atendiendo a las desiguales condiciones del poder de fuego argentino respecto de las capacidades del poder aéreo y de la artillería naval y de campaña enemigos. Asimismo -como pude constatar en las entrevistas a oficiales, suboficiales y soldados veteranos- la unidad se mantuvo cohesionada y en buen estado físico y moral durante toda la guerra. ${ }^{13}$ Cuando en la mañana del 14 de junio se produjo el cese el fuego sólo dos hombres del Grupo de Artillería 3 habían perdido la vida en combate -el teniente Alberto Rolando Ramos y el cabo primero Ángel Fidel Quispe- y otros veinticinco resultaron heridos. Las tropas argentinas en Puerto Argentino fueron hechas prisioneras. Los oficiales subalternos, suboficiales y soldados fueron enviados por los británicos a Puerto Madryn donde llegaron con otros combatientes argentinos entre 18, 19 y 21 de junio; en tanto que oficiales superiores y oficiales jefes y unos pocos oficiales subalternos y suboficiales del Ejército, Armada y Fuerza Aérea permanecieron prisioneros de guerra hasta que fueron trasladados a la mencionada localidad donde arribaron el 14 de julio. Entre estos últimos estaba Balza.

\section{Instrucción, adiestramiento y alistamiento de una unidad de artillería de campaña}

Como otras unidades de artillería, la organización y funcionamiento del Grupo de Artillería 3 era planificada y ejecutada anualmente con vistas a afrontar una guerra convencional, esto es, contra Fuerzas Armadas de otro Estado, considerando especialmente hipótesis de conflicto vecinales.

Balza fue designado jefe de la unidad el 31 de octubre de 1979 y asumió el 20 de diciembre. Esa jefatura era la oportunidad que esperaba para modelar un grupo de artillería según la idea que se había formado a lo largo de casi treinta años. Se concentró inmediatamente en la instrucción y adiestramiento del personal y el alistamiento de su unidad. El teniente Oscar Martínez Conti era su oficial de personal. Había arribado al Grupo de Artillería 3 a fines de 1980 y recuerda que Balza:

\footnotetext{
${ }^{11}$ Balza era el oficial del arma de artillería del Ejército de más alta jerarquía destinado en Malvinas.

${ }^{12}$ El 12 de junio le sería agregado otro cañón SOFMA calibre $155 \mathrm{~mm}$ del Grupo de Artillería 121 y en los combates finales por la defensa de Puerto Argentino un cuarto cañón ese tipo que no llegaría a emplearse.

13 El reconocimiento de esa cohesión grupal no excluye la existencia de algunos conflictos interpersonales y sanciones disciplinarias impuestas por Balza a algunos miembros de la unidad, como puede apreciar en entrevistas a veteranos y en la lectura del documento oficial: Balza, Martín. Informe de Operaciones del Grupo de Artillería 3, 6 de agosto de 1982.
} 
“... siempre estaba muy concentrado en la profesión. Lo normal era que estuviera en actividad entre las siete de la mañana y las diez de la noche. Y los sábados a la mañana nos venía a buscar [...] El Grupo de Artillería 3 fue exitoso o tuvo un buen desempeño en Malvinas porque cumplimos con lo que se esperaba de la organización. Hicimos aquello para lo que nos habíamos preparado durante dos años. No hicimos nada por encima de eso. En 1981 tuvimos catorce salidas al terreno. Por eso siempre digo: la explicación de por qué el buen desempeño es el número catorce. La guerra se ejercita en el terreno. Con la salvedad, claro, que ni el aula ni el terreno, logran representar realmente lo que pasa en la guerra. Pero la ecuación del terreno es irreemplazable. Normalmente salíamos al campo de instrucción del cuartel o al Campo Ávalos cerca de Monte Caseros. Esas salidas le dieron una habilidad técnica y táctica al Grupo. En 1981 hubo un recambio de oficiales. Balza armó un equipo de oficiales muy bueno". ${ }^{14}$

El mayor Carlos Milanese fue designado oficial de operaciones. Cuenta que en el año 1981:

“Teníamos muchísimo trabajo. El Grupo de Artillería 3 era una unidad seleccionada para experimentar la incorporación trimestral de soldados conscriptos. Uno tenía la unidad siempre instruida y operativa. Posiblemente la renovación [de la incorporación de conscriptos] por cuartos [trimestral] se efectuaba al interior de cada batería. El programa de alistamiento de la unidad preveía, por ejemplo, la marcha motorizada con los equipos y víveres hasta el lugar elegido para los ejercicios, entrar en posición, tiro de artillería, todo esto planteado en una operación terrestre. Balza tuvo a la unidad entrenándose todo el año en el terreno. La gente estaba ejercitada. En el país nadie tenía pensada una guerra contra el Reino Unido y tampoco en un territorio insular. Pero igual andábamos todo el tiempo y todo el año, marchas a pie de noche, haciendo adaptación y resistencia a la fatiga. Balza le ponía mucho énfasis a eso". ${ }^{15}$

En tiempos de paz, además de las Baterías Comando y Servicios, las unidades de artillería tenían dos Baterías de Tiro. En el caso específico del Grupo de Artillería 3 cada una disponía de seis piezas de artillería Oto Melara calibre de $105 \mathrm{~mm}$ incorporadas en el año 1981 en reemplazo de los obuses Schneider calibre de $105 \mathrm{~mm}$. Al frente de cada batería había un oficial jefe de batería (un teniente primero) y uno o dos oficiales de batería (teniente o subteniente). A su vez, en cada pieza de artillería había un suboficial jefe de pieza (sargento primero o sargento), un suboficial auxiliar (cabo primero o cabo) y seis soldados en el servicio de pieza con funciones como apuntador derecho, apuntador izquierdo, graduador (el que regula la espoleta a tiempo del proyectil) y dos abastecedores de munición. Entre los servidores de pieza uno cumplía el rol de comunicante.

Los soldados de una clase llamados a servir como conscriptos eran convocados mediante una cédula que les ordenaba presentarse en la sede del distrito militar correspondiente a su domicilio declarado en el documento nacional de identidad o el registro de enrolamiento. De acuerdo con Oscar Martínez Conti, a fines de 1981 el Ejército estableció un sistema experimental en la Brigada de Infantería III denominado "por cuartos", de modo que los relevos se hacían en forma trimestral para disponer de soldados instruidos y a la unidad operativa ciento por ciento durante todo el año. Por ello a fines de dicho año sólo se licenció al 25 por ciento de los soldados de la clase $1962 .{ }^{16}$ Con este sistema "experimental" la primera incorporación del año se producía en febrero-marzo y la última en noviembre-diciembre. De este modo: "Si de los seis sirvientes que

\footnotetext{
${ }^{14}$ Entrevista al general de brigada VGM (R) Oscar Martínez Conti. 14 de diciembre de 2015. Ciudad Autónoma de Buenos Aires.

15 Entrevista al teniente coronel VGM (R) Carlos Milanese. 17 de diciembre de 2015. Ciudad Autónoma de Buenos Aires.

${ }^{16}$ Martínez Conti, Oscar. "El Grupo de Artillería 3 en Malvinas". Revista Santa Bárbara No39. Buenos Aires. pp.56-60.
} 
tiene un Oto Melara estaban instruidos tres -el apuntador, el cargador y el que dispara- era suficiente; el resto movía las cajas". ${ }^{17}$ Para Guillermo Castillo:

"El soldado de clase 62 estaba muy bien instruido en el Oto Melara. El observador adelantado sabía hacer bien las apreciaciones del blanco, correcciones. El comunicante tenía el conocimiento del vocabulario específico. En la pieza el apuntador derecho e izquierdo, el graduador de la espoleta de tiempo [del proyectil] eran tipos despiertos. Una vez aprendida la tarea tenía que hacerse en forma rutinaria bajo el control del jefe de pieza y del oficial a cargo. Por eso cuando los soldados de la clase 62 fueron reincorporados en abril del 82 sólo hubo que refrescarles los conocimientos". ${ }^{18}$

La rutina diaria comenzaba en el cuartel alrededor de las 06:00 horas con la formación en la plaza de armas, práctica de orden cerrado, estudios y prácticas de artillería: conocimientos teóricos y prácticos de tiro de artillería, topografía, comunicaciones, servicio de pieza, reglamentos militares, servicio interno y en guarnición. La instrucción estaba a cargo principalmente de los suboficiales, pero los oficiales de las baterías también intervenían en algunas instancias como cuando efectuaban simulacro de tiro o tiro de artillería. 19 "Aprendíamos los roles de servicio de pieza, observador adelantado y centro de dirección de tiro [CDT]". ${ }^{20}$ Hacían entrenamiento en la pista de combate y de atletismo que había en la unidad. Salían a correr por los alrededores o hasta la ciudad. En la cancha de polo lindera al cuartel practicaban tiro de artillería con munición de subcalibre que no producía explosión pero servía para batir blancos. ${ }^{21}$

"Balza estaba presente en todo el proceso de instrucción de los soldados como artilleros. La instrucción era estricta, permanentemente controlada y evaluada. Por ejemplo, el viernes íbamos a tirar a un campo detrás de Zapadores -Lomas Valentina. La zona de blanco y punto base era El Hachazo. Salíamos a tirar [con los obuses]. A la tarde llegaba Balza a controlar el tiro y podía decir: 'Tal cosa no está bien, se quedan hasta mañana'... En la semana salíamos a hacer gimnasia y a correr con él. [...] La práctica de tiro de artillería era intensiva, permanente, en la instrucción. También íbamos al Campo Ávalos como unidad a hacer ejercicios propios o participando en los de la Brigada. Podíamos tirar 30 o 40 tiros por pieza [...] En junio se hizo un ejercicio helitransportado en Campo Ávalos, sólo con los cuadros y con una pieza de cada batería. Desgraciadamente esto último no pudimos ponerlo en práctica en Malvinas por la falta de medios [helicópteros] y, por eso, teníamos que trasladar las piezas con vehículos". ${ }^{22}$

La unidad tenía sistematizados y bien incorporados sus Procedimientos Operativos Normales (PON) para realizar diferentes actividades con automaticidad, facilitar "su ejecución, el comando y el control del jefe del elemento de menor nivel" y "superar las exigencias desconocidas" en las contingencias que ocurren durante el combate. ${ }^{23}$ Balza definió los PON como:

"Algo que el hombre aprende en cada actividad. Automatiza todo. Por ejemplo: el procedimiento de tiro... Se evita de este modo dar órdenes innecesariamente para cumplir con tareas rutinarias. Con darse una señala alcanza. Llevábamos un orden para todo. Pero lograr eso lleva tiempo en cualquier unidad. Y continuidad en el trabajo con oficiales,

\footnotetext{
17 Entrevista al teniente general VGM (R) Martín Antonio Balza. 23 de marzo de 2016. Ciudad Autónoma de Buenos Aires.

${ }^{18}$ Entrevista al sargento primero VGM (R) Guillermo Castillo. 22 de abril de 2016. Paso de los Libres.

${ }^{19}$ Entrevista al ex-soldado Julio Palacio. 23 de febrero de 2016. Paso de los Libres.

20 Entrevista a ex-soldado Ramón Elías Mango. 23 de febrero de 2016. Paso de los Libres.

${ }^{21}$ Entrevista a ex-soldado Hugo Mango. 23 de febrero de 2016. Paso de los Libres.

${ }^{22}$ Entrevista al sargento primero VGM (R) Guillermo Castillo. 22 de abril de 2016. Paso de los Libres.

${ }^{23}$ Martínez Conti, Oscar. "El Grupo de Artillería 3...” op.cit. pp.56-60.
} 
suboficiales y soldados. Yo ya había iniciado eso en 1980 y para el 2 de abril de 1982 llevaba más de dos años ejercitándolo". ${ }^{24}$

A aquellos soldados que contaban con estudios secundarios completos se les ofrecía la posibilidad de efectuar el curso de AOR-Auxiliar de Oficial de Reserva. En 1981 los conscriptos que se sumaron a esa modalidad fueron incorporados a la Batería de Tiro "B". Su instrucción como soldados y artilleros era más rigurosa, pues finalizaban el servicio militar con el grado de subteniente de reserva. Ese año optaron por esa modalidad entre cuarenta y cinco y sesenta, pero concluyeron unos siete o cinco. La instrucción que efectuaban era como observador adelantado, operador de plano horizontal (que maneja cartografía y realiza cálculos para el tiro de artillería) y oficial de batería. Asimismo, esa modalidad del servicio militar tenía como "beneficio" poder terminar la conscripción en noviembre cuando se producía la primera baja de soldados. ${ }^{25}$

Como mencionara Oscar Martínez Conti, las salidas de la unidad al terreno para ejercitar eran frecuentes -algunos testimonios señalan una vez al mes- pudiendo incluir marchas a campo traviesa con materiales y equipo desde Paso de los Libres hasta la pequeña localidad de Yapeyú distante a unos 75 kilómetros al norte por la costa del Río Uruguay, o trasladarse hasta el campo de instrucción que el Ejército disponía unos kilómetros más al sur en el denominado Campo Ávalos. En este último practicaban tiro con los obuses Oto Melara calibre de $105 \mathrm{~mm}$. El sargento José María González Fernández recuerda que en 1981: "Vivíamos de instrucción en el campo. A cualquier hora había alistamiento. Balza estaba presente todo el tiempo". ${ }^{26} \mathrm{Y}$ el soldado Elías Mango: "En Campo Ávalos hicimos tiro [de artillería] cercano por encima de la tropa [de infantería] a menos de 600 metros. Un tiro muy delicado, riesgoso. En la guerra tuvimos que tirar sobre tropa propia muchas veces y nosotros ya teníamos esa experiencia encima". ${ }^{27}$ Asimismo para el sargento mecánico de munición y explosivos Luis María Rodríguez:

"Ese año la instrucción fue intensa porque se recibieron los obuses Oto Melara [de 105 $\mathrm{mm}$ ], pero cuando entregamos los Schneider [de 105] $\mathrm{mm}$ lo hicimos agotando la munición que tenían asignada. Por eso ese año tiramos con los dos obuses. Y si bien cada uno tiene su particularidad, los principios son los mismos. Optimizamos al máximo la instrucción. Debemos haber tirado el doble de lo que se hace en un año. Yo le digo a los jóvenes que lo que hicimos en Malvinas lo hicimos por lo que habíamos hecho en la instrucción [...] Eso es porque teníamos entrenamiento y el equipo preparado. Nos pasaban revista. Había una orden de ingreso y salida con el bolso alistado. Después nos dimos cuenta que no es lo mismo cuando está todo arreglado. Todos teníamos cada uno el casco, el fusil y dotación de munición. Todo listo. Terminaba la formación y se ordenaba alistamiento y cada uno iba a buscar armas, casco, munición y bolsón. Al principio nos costó. No le veíamos la importancia. Después nos cayó la ficha ¿Por qué tengo que poner ese orden? Para que cada uno sepa rápidamente y para que el equipo de uno sirva para otro. La munición de las piezas yo ya las tenía preparadas por batería y pieza de cada batería. Cada una tenía la dotación inicial. En el caso de los Oto Melara [calibre de $105 \mathrm{~mm}$ ] 70\% de proyectiles con espoleta instantánea, 20\% con espoleta a tiempo y 10\% con proyectiles fumígenos. 190 disparos por pieza. Yo había entendido cómo era el sistema". ${ }^{28}$

Miguel Ángel Rubio dice que Balza ordenaba cada mes o mes y medio el alistamiento de la unidad para chequear que estuviera pronta para su desplazamiento y eventual empeñamiento en

\footnotetext{
${ }^{24}$ Entrevista al teniente general VGM (R) Martín Antonio Balza. 23 de marzo de 2016. Ciudad Autónoma de Buenos Aires.

${ }_{25}$ Entrevista al suboficial mayor VGM (R) José María González Fernández. 22 de febrero de 2016. Paso de los Libres.

26 Entrevista al suboficial mayor VGM (R) José María González Fernández. 22 de febrero de 2016. Paso de los Libres.

${ }^{27}$ Entrevista a ex-soldado Ramón Elías Mango. 23 de febrero de 2016. Paso de los Libres.

${ }^{28}$ Entrevista al suboficial mayor VGM (R) Luis María Rodríguez. 23 de abril de 2016. Paso de los Libres.
} 
combate. "Cada uno sabía lo que tenía que hacer. El alistamiento lo podía ordenar a cualquier hora. Por ejemplo a la madrugada y sin previo aviso. Un sábado también. Una vez lo hizo a las dos de la mañana. Nos reunió en la plaza de armas del cuartel y nos dio la orden de marchar hasta Yapeyú. Nosotros para adentro lo puteábamos, pero eso hizo la diferencia en Malvinas". ${ }^{29}$

Los soldados debían aprender a identificar una cuestión básica y vital para la supervivencia en combate de los miembros de una batería de artillería: reconocer el tiempo que demora un proyectil entre el "estampido de boca" en las piezas del enemigo hasta su caída en la posición propia o sus proximidades. Este fue también un conocimiento práctico clave posteriormente en la Guerra de Malvinas, si bien, como apuntaba un suboficial: "Ahí [en las Islas Malvinas] tuvimos que aprender que las fragatas [británicas] tiraban con marcha cadencia y, por eso, era difícil diferenciar el estampido de boca [en el cañón de la fragata] y el estampido de explosión [en la posición propia]". ${ }^{30}$ Es decir, la instrucción en tiempos de paz era fundamental, pero la guerra imponía siempre novedades, contingencias no previstas, que había que comprender y saber lidiar con ellas para ser eficientes en combate y, por supuesto, sobrevivir.

Ese año 1981 el Grupo de Artillería 3 estaba tan bien preparado física, militar y moralmente que enviaron una representación para participar de una competencia de ejercicios de infantería -que comprendía tiro, lanzamiento de granada, pista de combate y marcha o carrera a campo traviesaorganizada por la Brigada en Curuzú Cuatiá y la ganaron. "El comandante de la Brigada quería matar a los infantes ¡les habían ganado los artilleros en su propia especialidad!". ${ }^{31}$ Contar con el personal instruido y la unidad alistada en forma permanente fue un factor decisivo cuando el Grupo de Artillería 3 recibió la orden de marchar al sur argentino a principios de abril de 1982 y, obviamente, también en la guerra.

Por último, señalemos que conforme a las "directivas de educación” impartidas por el Ejército el discurso de la "lucha contra la subversión" estaba presente en las concepciones emanadas de las mismas. Sin embargo, Balza sostiene que ese discurso no tenía consecuencias prácticas en la instrucción y alistamiento del Grupo de Artillería 3, pues era unidad no tenía responsabilidad territorial excepto en lo relativo al control de las rutas cercanas al cuartel. En consecuencia, en los años en que estuvo al frente del mismo -1980, 1981 y parte de 1982- se priorizaron las actividades de instrucción y alistamiento propias de una unidad de artillería de campaña. ${ }^{32}$

\section{La artillería en la Guerra de Malvinas}

Si la inminente conflagración con Chile había sido el resultado de tensiones acumuladas entre ambos países durante un siglo de hipótesis de conflicto vecinales, la recuperación de las Islas Malvinas por la Argentina el 2 de abril de 1982 y el inicio de la guerra con Gran Bretaña fue un hecho para el cual el Ejército Argentino no se había preparado a lo largo de toda su historia. Federico Lorenz observa que de cada diez combatientes argentinos, en el Ejército siete eran soldados conscriptos de las clases 1962 y 1963 -los de esta última con escasa o nula instrucción militar pues habían sido incorporados a principios de $1982 .{ }^{33}$ Por el contrario las unidades británicas se integraban en su totalidad por militares profesionales y estaban tecnológicamente mejor equipadas. Estos dos factores no fueron los únicos que decidieron el conflicto en favor de Gran Bretaña, pues a pesar del buen desempeño de muchos oficiales, suboficiales y soldados argentinos, no estaban en condiciones para afrontar una guerra convencional contra una potencia

\footnotetext{
${ }^{29}$ Entrevista al suboficial mayor VGM (R) Miguel Ángel Rubio. 22 de febrero de 2016. Paso de los Libres.

${ }^{30}$ Entrevista al sargento primero VGM (R) Guillermo Castillo. 22 de abril de 2016. Paso de los Libres.

${ }^{31}$ Entrevista al suboficial principal VGM (R) Jorge Quiroz. 23 de febrero de 2016. Paso de los Libres.

32 Entrevista al teniente general VGM (R) Martín Antonio Balza. 4 de mayo de 2016. Ciudad Autónoma de Buenos Aires.

${ }^{33}$ Lorenz, Federico. Malvinas. Una guerra argentina... op.cit. p.70.
} 
mundial; más aún si se considera que desde mediados del siglo XX el pensamiento y accionar militar argentino se había orientado hacia conflictos internos en el marco de la "doctrina de la seguridad nacional" y que desde 1930 las conducciones castrenses habían intervenido en la política nacional y en los asuntos del gobierno civil del país.

Ahora bien, si bien subscribo la anterior afirmación, considero que es una explicación genérica que no puede aplicarse sin más al desempeño táctico que tuvieron jefes, oficiales, suboficiales y soldados argentinos en la Guerra de Malvinas. Del análisis del Informe de la Comisión de Análisis y Evaluación de las Responsabilidades del Conflicto del Atlántico Sur-conocido como Informe Rattembach-se desprende el destacado papel como jefes tácticos en las operaciones terrestres desplegado por el teniente coronel Antonio Martín Balza -jefe del Grupo de Artillería 3- teniente coronel Mohamed Alí Seineldín -jefe del Regimiento de Infantería Mecanizado 25-, el mayor Aldo Rico jefe de la Compañía de Comandos 602-, el teniente coronel Carlos Alberto Quevedo -jefe del Grupo de Artillería Aerotransportada 4-, el teniente coronel Héctor Lubín Arias -jefe del Grupo de Artillería de Defensa Aérea 601- y el capitán de fragata Carlos Hugo Robacio -comandante del Batallón de Infantería de Marina $5 .^{34}$

Comparando el poder de fuego de la artillería de campaña de las fuerzas argentina y británica, esa asimetría se expresaba en la disposición por parte de la primera de 18 obuses de $105 \mathrm{~mm}$ Oto Melara del Grupo de Artillería 3, 17 obuses de $105 \mathrm{~mm}$ Oto Melara del Grupo de Artillería Aerotransportada 4, 3 cañones SOFMA de $155 \mathrm{~mm}$ (el cuarto no llegó a estar operativo) procedentes de los Grupos de Artillería 101 y 121 agregados al Grupo de Artillería 3 y 6 obuses de $105 \mathrm{~mm}$ Oto Melara de la Batería de Artillería del Batallón de Infantería de Marina 5 (total 44 piezas). Recordemos que los obuses argentinos de $105 \mathrm{~mm}$ tenían un alcance de 10.200 metros y los cañones de $155 \mathrm{~mm}$ de 20.000 metros. En tanto que la artillería de campaña británica contaba con cañones de $105 \mathrm{~mm}$ con alcance de 17.000 metros: 18 piezas el Regimiento 4 Aerotransportado de la Artillería Real, 18 piezas el Regimiento 29 de Artillería Real y 18 piezas del Regimiento 66 de la Artillería Real (total 54 piezas). El coronel (R) Horacio Rodríguez Mottino concluye, pues, que la relación de potencia entre ambas artillerías de campaña era favorable a los británicos en proporción de $3 / 1 .^{35}$ Para Balza esas asimetrías se veían acrecentadas a favor de los británicos por una relación desfavorable para los argentinos entre la extensión del perímetro de Puerto Argentino que debía defender y la cantidad relativamente insuficiente de piezas de artillería que disponían. A su vez, las dificultades se crecentaban toda vez que se disponía de muy pocos proyectiles de iluminación de $105 \mathrm{~mm}$ y munición de $155 \mathrm{~mm}$, radares adecuados para la adquisición de blancos y medios de comunicación, ausencia helicópteros para la movilidad del material, y deficientes en las coordinaciones con algunas unidades de infantería del Ejército para reglar el tiro de artillería. ${ }^{36}$

¿Qué factores coadyuvaron al cumplimiento de las misiones del Grupo de Artillería 3 y cuáles los limitaron? De acuerdo con la evaluación que Balza efectuó del desempeño de su unidad en combate en la inmediata posguerra en el Informe de Operaciones del Grupo de Artillería 3 del 6 de agosto de 1982, destacaba entre los primeros: 1) eficiente nivel de instrucción de cuadros y tropa; b) empleo de los soldados de la clase 1962 con sistema de incorporación trimestral y selección de personal de tropa dejando en el continente aquel que no era estrictamente necesaria; 3) óptimo estado físico del personal; 4) material de artillería y radar Rasit en buen estado; 5) eficientes operadores de radar Rasit; 6) buen funcionamiento del material de comunicaciones; 7) intensificación de la instrucción nocturna antes del inicio de las operaciones; 8) eficiente ensamble técnico en el servicio de pieza, observadores adelantados, centro de dirección de tiro y operadores de equipos de comunicaciones; 9) operar medios de comunicación con el personal de

\footnotetext{
34 Junta Militar, Comisión de Análisis y Evaluación de las Responsabilidades del Conflicto del Atlántico Sur, Buenos Aires, 1983.

35 Rodríguez Mottino, Horacio. La artillería argentina en Malvinas, Buenos Aires, Clío, 1984, pp.19-20-27-28-56.

${ }^{36}$ Balza, Martín. Malvinas. Gesta e incompetencia, Buenos Aires, Atlántida, 2003, p.126.
} 
cuadros; 10) supervisión en todos los niveles de los aspectos ordenados relativos al mantenimiento de la moral, favoreciendo positivamente en el "espíritu de cuerpo" y el "índice disciplinario". ${ }^{37}$ En tanto que los factores que a su juicio los limitaron fueron: 1) falta de radares contra-armas (contra-morteros y contra-artillería), radares tipo Ratac para la dirección de tiro de artillería (especialmente para los cañones SOFMA de $155 \mathrm{~mm}$ ) y computadoras para el tiro (tipo David); 2) limitados conocimientos de las posibilidades y limitaciones de la propia artillería por parte de los elementos de maniobra; 3) carencia de proyectiles de iluminación para los obuses Oto Melara de $105 \mathrm{~mm}$ y la que se disponía para los cañones SOFMA de $155 \mathrm{~mm}$ fue provista por la Armada; 4) falta de movilidad, especialmente aérea (helicópteros) para el traslado de las piezas, municiones y personal; 5) necesidad de más piezas de artillería de $155 \mathrm{~mm}$; 6) falta de instrucción integrada entre el elemento de maniobra (principalmente las unidades de infantería del Ejército) y el apoyo de fuego. ${ }^{38}$ Asimismo Balza resaltó otros factores que también contribuyeron a favor de su misión como el buen estado sanitario de sus hombres al cuidado del oficial médico, el mantenimiento de la moral a cargo del oficial de Personal, la acción integral del oficial de Intendencia. Y otros que la dificultaron como la recepción de los "agregados" oficiales, suboficiales y soldados de otras unidades incorporados al Grupo de Artillería 3- a escasas horas de partir al Teatro de Operaciones y el hecho de que en términos generales sus conocimientos acerca de la técnica del arma (artillería) no estaba de acuerdo con su jerarquía y en algunos casos no contaban con adecuado estado físico que exige el combate, para lo cual "tuvieron que tomar el ritmo propio de la unidad durante el desarrollo de las operaciones" y "algunos no lo lograron". 39

En definitiva, la adecuada performance del Grupo de Artillería 3 en la defensa perimétrica de Puerto Argentino durante la Guerra de Malvinas fue consecuencia de: a) un calificado y experimentado liderazgo militar forjado en un proceso de educación y desarrollo de la carrera profesional de Balza como oficial de artillería y de Estado Mayor que se extendió a lo largo de treinta años desde que ingresara al Colegio Militar de la Nación en 1952 hasta que asumió la jefatura del Grupo de Artillería 3 en diciembre de 1979; b) oficiales, suboficiales y soldados conscriptos de la clase 1962 debida e intensamente instruidos en las operaciones propias de la artillería de campaña y alistados con más de un año de trabajo en el cuartel y en salidas al terreno; c) una unidad cohesionada en tiempos de paz que -que aunque incorporó personal "agregado" poco antes de cruzar a las Islas Malvinas, pasó "disminuida" desde el continente dejando el personal que no estaba preparado para el combate a juicio del jefe de la unidad, y que aunque experimentó en la guerra los conflictos naturales que cualquier grupo humano atraviesa en esas circunstancias extraordinarias no perdió su integración social y su eficacia en combate hasta día del cese del fuego en la mañana del 14 de junio de 1982. Ese destacado desempeño del Grupo de Artillería 3 se vio refrendado en la posguerra en las condecoraciones otorgadas a su jefe y algunos oficiales, suboficiales y soldados y por un hecho adicional: es una unidad del Ejército en la que sus veteranos de guerra -oficiales, suboficiales y soldados- se reúnen anualmente para conmemorar su "bautismo de fuego" en la Guerra de Malvinas. ${ }^{40}$

Ahora bien, aquí es preciso señalar que la formación básica de un oficial artillero, el desarrollo de su carrera profesional como oficial subalterno en unidades operativas del arma y en la Escuela de Artillería y como oficial de Estado Mayor, se centraban en la doctrina y actividades específicas que la artillería de campaña o antiaérea tenía en la concepción y despliegue de operaciones del Ejército Argentino en una guerra convencional, esto es, en un conflicto contra un enemigo estatal

\footnotetext{
37 Balza, Martín. Informe de Operaciones... op.cit. pp.17-18.

38 Balza, Martín. Informe de Operaciones... op.cit. p.20.

39 Balza, Martín. Informe de Operaciones... op.cit. pp.21-22.

40 El contraste es elocuente con otras unidades del Ejército que combatieron en la Guerra de Malvinas cuyos veteranos mantienen históricos conflictos entre oficiales, suboficiales y soldados conscriptos que impiden tales conmemoraciones o reuniones compartidas.
} 
externo. ${ }^{41}$ En la siguiente sección sintetizaremos algunos de los temas que concentraban la atención de los oficiales artilleros del Ejército Argentino entre la década de 1950 y principios de la década de 1980.

\section{Temas profesionales de los oficiales artilleros: 1950-1982}

En un escenario de la defensa nacional y seguridad internacional dominado en el Cono Sur por hipótesis de conflicto vecinales respecto de Chile y Brasil e hipótesis de conflicto internas contra la "subversión comunista" en el marco de la guerra Fría, la formación profesional de los militares argentinos sumó a la tradicional preparación para una guerra convencional contra Fuerzas Armadas de otros Estados, las enseñanzas doctrinarias de la "guerra revolucionaria" de raíz francesa desde la segunda mitad de la década de 1950 y de la "guerra contrainsurgente" norteamericana desde principios de la de $1960 .{ }^{42}$

En la Argentina estas últimas influencias han sido estudiadas procurando comprender su incidencia en las concepciones y prácticas represivas en la seguridad interior y en el recurso al terrorismo de Estado. Sin embargo, la formación profesional de los militares argentinos destinada a una guerra convencional ha sido notablemente desatendida por los científicos sociales. Es por ello que es necesario avanzar en el conocimiento de esta última, en particular, centrándonos en los oficiales del arma de artillería del Ejército Argentino, quienes como he mencionado más arriba tuvieron un destacado desempeño militar en el nivel táctico durante la Guerra de Malvinas. No es posible, entonces, entender esa eficiente performance en combate entre abril y junio de 1982 sin conocer más en profundidad cómo era la formación profesional de estos artilleros desde la segunda posguerra. Para dar cuenta de ello en un trabajo anterior efectué un relevamiento y análisis sistemático de artículos publicados en la Revista de Informaciones y en la Revista de la Escuela Superior de Guerra del Ejército entre el año 1950 y 1982, esto es, desde el número 287 (enerofebrero de 1950) al 463 (septiembre-diciembre de 1982), sumando 32 artículos referidos a temas de artillería. ${ }^{43}$

\footnotetext{
${ }^{41}$ No obstante ello, como señala Oscar Martínez Conti en el curso de la Guerra de Malvinas también se adquirieron aptitudes extraordinarias infrecuentes o impensadas en la planificación del adiestramiento o en la doctrina de la artillería de campaña: "Entre otras, batir hasta tres blancos en simultáneo con una misma subunidad, ejecutar tiro nocturno contra buques de guerra estacionados o en movimiento con datos de tiro obtenidos de la información proporcionada por un radar de vigilancia terrestre que se volcaban sobre la cartografía para luego obtener datos de tiro, localización, identificación de blancos y reglaje de tiro desde un helicóptero en un ambiente sin superioridad aérea, como así también el empleo de un sistema común de localización de blancos, para sortear las permanentes dificultades de la observación producto del rigor meteorológico imperante y para simplificar los requerimientos de apoyo de fuego de los elementos comprometidos en primera línea o de las tropas comando durante sus infiltraciones". Martínez Conti, Oscar. "El Grupo de Artillería 3..." op.cit. pp.56-60.

${ }^{42}$ Para Esteban Pontoriero no debe considerarse la "doctrina de la guerra revolucionaria" como un corpus uniforme, pudiendo distinguirse entre su concepción sobre la guerra contra el "comunismo" y un conjunto de métodos y técnicas. Para este historiador la influencia de la vertiente norteamericana se acrecentó como consecuencia de la crisis del Ejército francés tras su derrota en Argelia en 1962, por la renovada política de defensa y seguridad de Estados Unidos desde el triunfo de la Revolución Cubana en 1959, y por la resolución del conflicto interno en las Fuerzas Armadas Argentinas entre las facciones de "Azules" y "Colorados" en 1962-1963. Pontoriero, Esteban. De la conmoción interior a la guerra revolucionaria: legislación de defensa, pensamiento militar y caracterización de la amenaza a la seguridad interna en la Argentina (1958-1970), Tesis de Licenciatura en Historia, Universidad Nacional de Tres de Febrero, 2012.

${ }^{43}$ Soprano, Germán. "La formación profesional de los oficiales artilleros del Ejército Argentino entre la Segunda Posguerra Mundial y la Guerra de Malvinas". Ponencia presentada en el IX Encontro Nacional da Associaçao Brasileira de Estudos de Defesa, Associaçao Brasileira de Estudos de Defesa / Universidade Federal de Santa Catarina, Florianópolis, 2016. La Revista de Informaciones y la Revista de la Escuela Superior de Guerra son publicaciones profesionales editadas por la Escuela Superior de Guerra, institución educativa castrense -fundamental pero no exclusivamente- destinada a impartir los Cursos de Oficiales de Estado Mayor para oficiales del Ejército con el grado de capitán en los últimos años y de mayor en el primero. La Revista de Informaciones fue creada en el año 1912 y se publicó hasta el número 312 correspondiente a los meses de marzo/abril de 1954. Desde entonces fue reemplazada hasta la actualidad por la Revista de la Escuela Superior de Guerra dando continuidad a la numeración anterior.
} 
¿Quiénes publicaron esos artículos? En ese período y sobre esos temas, 22 oficiales del Ejército Argentino fueron autores, un extranjero y un civil (ingeniero) argentino. De los oficiales argentinos uno era general de división retirado, un coronel, 10 tenientes coroneles y 11 mayores, es decir, se trataba de oficiales superiores u oficiales jefes -en muchos casos se trataba de profesores y cursantes en la Escuela Superior de Guerra que publicaban trabajos resultantes de los cursos administrados por esta institución educativa. Dos artículos solamente fueron escritos en co-autoría y otro no mencionaba autoría pues era reproducción de un Reglamento de Artillería. Del total de autores, uno escribió cuatro artículos, otro tres y tres autores dos artículos cada uno. ${ }^{44}$

Los artículos publicados cuyo objeto general era la guerra comprendían: a) la guerra convencional entre Fuerzas Armadas o fuerzas militares estatales, tópico que constituía la principal temática profesional abordada por los oficiales argentinos en la Revista de Informaciones y luego en la Revista de la Escuela Superior de Guerra; b) la guerra revolucionaria, problematizada desde su introducción en la Argentina en 1956 bajo la influencia de la denominada "doctrina francesa"; c) y la guerra nuclear, tratada desde la Segunda Posguerra Mundial. ${ }^{45}$

En cuanto al contenido específico de los artículos sobre artillería, estos pueden clasificarse como conforme a las siguientes dimensiones objeto de análisis: a) doctrina (principios que orientan la comprensión y acción del arma de artillería en los escenarios de guerra convencional en que se espera sea empeñada); b) táctica de la artillería (empleo de los medios militares del arma en operaciones de guerra); c) materiales de la artillería (principalmente cañones y obuses) y equipos (de radar, comunicaciones, etc.); d) educación de los artilleros. Los artículos referidos a doctrina de la artillería predominaban en el conjunto, seguidos por aquellos enfocados en sus aplicaciones prácticas en la educación del personal. ${ }^{46}$

En definitiva, la interpretación que propongo de estos datos considero que permite avanzar en la puesta a prueba de esa hipótesis escasa o prácticamente no explorada por los científicos sociales en sus análisis del Ejército Argentino para los 1955 a 1983 que invocamos más arriba: que la formación básica y el perfeccionamiento en las academias militares y la planificación anual de las unidades operativas se continuaron concibiendo y desarrollando su instrucción y alistamiento principalmente con vistas a afrontar una guerra convencional. Lo dicho hasta aquí no contraviene sino que complementa los resultados de las investigaciones de los colegas que ha señalado con acierto que desde 1956 comenzó a gravitar en el Ejército Argentino la denominada "doctrina de la escuela francesa de la guerra revolucionaria" y desde principios de la década de 1960 la "doctrina norteamericana de la guerra contrainsurgente", confluyendo ambas en la denominada "doctrina de la seguridad nacional" que definió como hipótesis de conflicto a un enemigo

\footnotetext{
${ }^{44} \mathrm{La}$ selección de artículos recortada como unidad de análisis no comprende a todos los oficiales artilleros que fueron autores durante ese extenso período, pues el personal de esa arma también publicó sobre temas más amplios como política de defensa nacional, estrategia y doctrina militar, historia militar, seguimiento de conflictos internacionales, entre otras. Los autores eran predominantemente oficiales del Ejército Argentino, pero también podían publicar civiles y, ocasionalmente, oficiales de la Armada o Fuerza Aérea Argentina o miembros de Fuerzas Armadas de otros países que enviaban sus trabajos a estas revistas o bien que habían publicado en el extranjero y, traducción mediante, eran reproducidos en estas dos revistas. Normalmente ambas revistas publicaban unos seis números por año y cada uno tenía una cantidad variable de artículos, pudiendo considerarse estimativamente como promedio un total de siete, si bien algunos números especiales ofrecían solo un trabajo o la exposición de un ejercicio militar. Algunos números incluían discursos de autoridades militares e información institucional del Ejército o la Escuela Superior de Guerra.

45 Soprano, Germán. "La formación profesional... op.cit.

46 Soprano, Germán. "La formación profesional... op.cit. La importancia cualitativa y cuantitativa atribuida a los temas de doctrina de la artillería está relacionada con el hecho de que se trataba fundamentalmente de trabajos producidos por sus profesores o alumnos en el ámbito de la Escuela Superior de Guerra, o bien artículos enviados especialmente para su publicación por esa institución. Siendo, asimismo, el tratamiento de los temas relativos a táctica más propios de la Escuela de Artillería y los tópicos referidos a materiales a esta última o bien a la Escuela Superior Técnica.
} 
interno. Y sobre ese tema central para comprender la política nacional y, particularmente, el papel del Ejército en la misma y en la construcción de un orden represivo, disponemos de más detalladas investigaciones. ${ }^{47}$

\section{Reflexiones finales}

Por el contrario, no disponemos de estudios de caso sobre unidades operativas ni de trayectorias individuales y colectivas de oficiales y suboficiales del Ejército Argentino que permitan sopesar empíricamente el grado de aplicación -considerando diferentes jurisdicciones castrenses y tipos de unidades- de esta hipótesis acerca del énfasis otorgado a la formación básica y el perfeccionamiento en las academias militares y a la instrucción, adiestramiento y alistamiento de las unidades operativas para la guerra convencional entre 1956 y 1983, es decir, en los años en que las conducciones castrenses se constituyeron en actores decisivos de la política y las Fuerzas Armadas en organizaciones con funciones de represión política y social sobre la sociedad nacional.

No obstante, los indicios y resultados preliminares a los que es posible arribar con arreglo a una renovada interpretación de los estudios sobre las Fuerzas Armadas en esos años (incluyendo su participación en la Guerra de Malvinas) y mediante el recurso a investigaciones históricas y etnográficas como la efectuada para una biografía del teniente general VGM (R) Martín Antonio Balza, convocan a los científicos sociales a no descuidar el análisis de la educación de los militares y su desempeño profesional en torno de las concepciones y prácticas de la guerra convencional en la segunda mitad del siglo XX.

47 Sobre la "escuela francesa" en Argentina: Amaral, Samuel. "Guerra revolucionaria: de Argelia a la Argentina, $1957-$ 1962”, Investigaciones y Ensayos No48, 2011, Buenos Aires, pp.173-195. Robin, Marie-Monique. Escuadrones de la muerte. La escuela francesa, Buenos Aires, Sudamericana, 2005. Ranalletti, Mario. "La guerra de Argelia y la Argentina. Influencia e inmigración Argentina desde 1945”, Anuario de Estudios Americanos 62, 2, 2005, Sevilla, pp. $285-308$. Ranalletti, Mario. "Contrainsurgencia, catolicismo intransigente y extremismo de derecha en la formación militar argentina. Influencias francesas en los orígenes del terrorismo de estado (1955-1976)", en D. Feierstein (comp.), Terrorismo de estado y genocidio en América Latina, Buenos Aires, Prometeo, 2009, pp. 249-280. Ranalletti, Mario. "Una aproximación a los fundamentos del terrorismo de Estado en la Argentina: la recepción de la noción de 'guerra revolucionaria' en el ámbito castrense local (1954-1962)", Anuario del Centro de Estudios Históricos año 11, No11, 2011, Córdoba, pp.261-278. López, Ernesto. El primer Perón. Militar antes que el político, Buenos Aires, Capital Intelectual, 2009. Mazzei, Daniel. Bajo el poder de la caballería. El Ejército Argentino (1962-1973), Buenos Aires, Eudeba, 2012. Summo, Marcelo y Pontoriero, Esteban. "Pensar la 'guerra revolucionaria': doctrina antisubversiva francesa y legislación de defense en la Argentina (1958-1962)", Revista Universitaria de Historia Militar No3 Año 2, 2015, Cádiz, pp.285-305. Más ampliamente sobre la militarización de la seguridad interna: Calveiro, Pilar. Poder y desaparición. Los campos de concentración en Argentina, Buenos Aires, Colihue, 2006. Franco, Marina. Un enemigo para la nación. Orden interno, violencia y 'subversión'. 1973-1976, Buenos Aires, Fondo de Cultura Económica, 2012. Franco, marina. "'la represión estatal en la historia argentina reciente: problemas, hipótesis y algunas respuestas tentativas”, en: G. Águila, S. Garaño y P. Scatizza (coords.), Represión estataly violencia paraestatal en la historia reciente argentina, La Plata, Facultad de Humanidades y Ciencias de la Educación de la UNLP, 2016, pp.15-43. Pontoriero, Esteban. "Estado de excepción y contrainsurgencia: el Plan CONINTES y la militarización de la seguridad interna en la Argentina (1958-1962)", Contenciosa. Revista sobre violencia politica, represiones y resistencias en la historia lationamericana Año III No4, 2015, Santa Fe, pp.1-16. Pontoriero, Esteban. "La seguridad interna como teatro bélico: legislación de defensa y contrainsurgencia en la Argentina (1966-1973)", Contracorriente. Revista de historia social y literatura de América Latina vol.13 No1, 2015, Raleigh pp.150-170. Pontoriero, Esteban. "Preparativos de guerra": Ejército, doctrina antisubversiva y planes represivos en los orígenes del terror de Estado, 1973-1976", Revista Universitaria de Historia Militar No10 vol.5, 2015, Cádiz, pp.319339. Pontoriero, Esteban. "En torno a los orígenes del terror de Estado en la Argentina de la década de los setenta", Papeles de Trabajo 10 (17), 2016, Buenos Aires, pp.30-50. Scatizza, Pablo. "Represión clandestina en la Argentina de los setentas. Algunas reflexiones sobre sus posibles puntos de partida". Contracorriente. Revista de historia social y literatura de América Latina vol.12 No3, 2015, Raleigh pp.138-177. "Soprano, Germán. "El Ejército Argentino en democracia: de la "doctrina de la seguridad nacional" a la definición de las "nuevas amenazas" (1983-2001)", Revista Universitaria de Historia Militar $\mathrm{N}^{\circ} 7$ vol.4, 2015, Cádiz, pp.86-107. Aquí también advierto que no es intención de este trabajo proveer un estado del arte sobre la literatura sobre este tema, sino encuadrar los argumentos de este artículo en diálogo con las investigaciones de indispensable referencia para pensarlo. 
En otras palabras, apoyándonos en los resultados de la labor de otros colegas consideramos que las doctrinas de la guerra revolucionaria y contrainsurgente se enseñaban en la Escuela Superior de Guerra, se efectuaban ejercicios en los que se ponían en práctica sus concepciones, e incluso orientaron la legislación sobre la defensa y la seguridad nacional del período 1956-1983. ${ }^{48}$ Pero al mismo tiempo creemos que la formación básica en el Colegio Militar de la Nación, el perfeccionamiento en las Escuelas de las Armas y el Curso de Estado Mayor de la Escuela Superior de Guerra, así como la planificación anual de la instrucción, adiestramiento y alistamiento de las unidades de infantería, caballería, artillería, ingenieros y comunicaciones, continuaron centrándose en las concepciones y prácticas de la guerra convencional. La trayectoria profesional de Balza y la reconocida performance de la artillería de campaña y antiaérea en la defensa perimetral de Puerto Argentino, confirmarían esa hipótesis; en tanto que podrá alegarse en contrario el predominantemente inadecuado desempeño de las unidades de infantería en las campañas terrestres de la Guerra de Malvinas como un indicador patente de un Ejército más preparado para actuar como fuerza policial de sus conciudadanos -combatiendo a un "enemigo interno"- que como una organización en condiciones de afrontar los desafíos de una guerra convencional.

Por último, quisiera señalar que para continuar profundizando en la indagación empírica de la hipótesis que exploramos en este artículo será preciso, asimismo, reconocer adecuaciones o modulaciones históricas particulares de tiempo, espacio y en relación con los actores castrenses analizados. ${ }^{49}$ Destaco al menos dos. Por un lado, que en las especialidades como la inteligencia militar y en las compañías de comandos el peso específico de las concepciones de la guerra revolucionaria y de la guerra contrainsurgente, seguramente tendrá una gravitación práctica mayor e incluso prevalente en su formación, capacitación y en la planificación anual de sus elementos. ${ }^{50}$ Por otro lado, no debe presuponerse a partir de la hipótesis que enunciamos que los artilleros o el personal de cuadros de las otras armas de combate no tuvieron responsabilidades en el terrorismo de Estado durante el autodenominado "Proceso de Reorganización Nacional", pues conforme a las responsabilidades jurisdiccionales que oficiales superiores y jefes asumían como comandantes de área, zona o subzona quedaban orgánicamente involucrados con sus unidades en la represión clandestina. ${ }^{51}$ Es por ello que las influencias teóricas y prácticas comprendidas ampliamente en el concepto de "doctrina de la seguridad nacional" eran conocidas con diferentes formas y grados de apropiación y, eventualmente, ejercidas por los artilleros.

\footnotetext{
48 Tal como puede constatarse por los análisis de la literatura citada en la nota a pie anterior.

$49 \mathrm{Al}$ respecto, Gabriela Águila ha advertido sobre la necesidad de reconocer "las variaciones y diversidades locales y/o regionales en la implementación de la represión tan importantes como la sistematicidad del accionar represivo diseñado e implementado desde el Estado. Ello obliga a considerar no sólo las relaciones entre el diseño del plan 'desde arriba' desde el aparato estatal/nacional y su implementación a escala local/regional sino también la disponibilidad de recursos y los variables grados de autonomía en el accionar de las fuerzas intervinientes". Águila, Gabriela. "La represión en la historia reciente argentina: fases, dispositivos y dinámicas regionales", en: G. Águila y L. Alonso (coords.), Procesos represivos y actitudes sociales. Entre la España franquista y las dictaduras del Cono Sur, Buenos Aires, Prometeo, 2013, p.99.

50 Para el caso de la inteligencia del Ejército en la última dictadura: Infojus. El Batallón de Inteligencia 601, Buenos Aires, Ministerio de Justicia y Derechos Humanos de la Nación, 2015. Para las compañías de comandos: Ruiz Moreno, Isidoro. Comandos en acción. El Ejército en Malvinas, Buenos Aires, Booket, 2007. También: Pontoriero, Esteban. "El tratamiento de los prisioneros de 'guerra subversiva' en los reglamentos de contrainsurgencia del Ejército argentino (1955-1976)", Revista Izquierdas No19, 2014, pp.131-142.

${ }^{51}$ Esto último puede verificarse con los estudios precursores de: D’Andrea Mohr, José Luis. Memoria debvida Colihue, Buenos Aires, 1999; Mittelbach, Federico y Mittelbach, Jorge. Sobre áreas u tumbas. Informe sobre desaparecedores, Sudamericana, Buenos Aires, 2000. También los avances en los juicios por crímenes de lesa humanidad reconocen entre procesados y condenados a oficiales y suboficiales de todas las armas del Ejército Argentino. El propio Balza fue vinculado en algunas denuncias que trascendieron en la prensa -sin que se encuentre procesado judicialmente ni existan evidencias para involucrarlo- con el funcionamiento en 1980 del centro de detención clandestina "La Polaca", próximo a Paso de los Libres, cuando era jefe del Grupo de Artillería 3.
} 